\title{
MANAGEMENT OF INDIRECT COSTS - MATHEMATICAL METHODS FOR COST ALLOCATION
}

\author{
S. Deevski* \\ Department of Industrial Business, University of National and World Economy, Sofia, Bulgaria
}

\begin{abstract}
The purpose of this paper is to look into the challenges of management of indirect costs in business organizations and to propose solutions to those problems. The paper starts with an introduction to the importance of understanding the concept of overhead costs and why it is often crucial for the management of the business organizations to classify, analyze and manage them. Particular problems to the allocation of indirect costs arise when supporting departments provide mutual services to each other. In these situation the management has two options - to ignore the mutual provision of services and account for the overheads as if there were no such services or to use simple cost allocation methods. This approach might not lead to reliable information required for taking sound management decision. With the advancement of technologies, the problem of obtaining timely and reliable information about the cost structure of cost objects (products, services, departments, etc.) could be resolved in an effective and efficient way using a third option. Namely, the utilization of mathematical methods for indirect cost allocation. The author performed a survey among managers of business organizations exploring whether they would use this approach and the results turned out to be positive.
\end{abstract}

Key words: cost accounting, management accounting, support department, cost allocation

\section{INTRODUCTION}

Allocating manufacturing overhead directly impacts business's balance sheet and income statement. It helps company's decision making, especially in terms of pricing. If product pricing is based only on the direct costs, this will seriously cut the profits. Those expenses are incurred no matter what and they should be attributed to the goods produced, which will naturally increase the price to cover for them. In competitive markets, it is crucial, whether the product will meet the needs of consumers and how it will be priced. For a company to be competitive, it needs to be able to adapt its products and their prices to the market. In this sense, allocating overhead can also help looking for ways to cut costs. It can be a motivator for different departments to improve the efficiency of their products and reduce overheads. In order to ensure the

\footnotetext{
*Correspondence to: Stoyan Deevski, Department: Industrial Business, University of National and World Economy, 1404 Sofia, 6 Kestenova gora, str., Telephone number: +359 885861 392, E-mail address: sdeevski@unwe.bg
}

company records are correct, the understanding how to reasonably and responsibly allocate these costs is essential.

\section{CHALLENGES OF MANAGEMENT OF INDIRECT COSTS}

The management of indirect costs has long been identified as one of the most complex areas to manage. For an accurate cost financial reporting we need a proper allocation of indirect costs. They can be challenging to define and distribute properly, but once they are, they can make a significant impact on the budget and help with staffing, and other important decisions. Clear connection between indirect expenses and the profit is often missing, which is not the case with direct costs. For example, material and labor costs are very visible to management and can be estimated and controlled directly. However, the nature of indirect cost is such that the expenses are spread over a number of expense accounts with various types of expenditures occurring unevenly over the year. Increases in indirect expenses result from a large number of unrelated actions taken by numerous managers 
and may be less apparent. Management must constantly be aware of and understand such costs in detail in order to effectively control them.

\section{Complexity}

Direct costs are directly associated with a cost object. The two have an immediately apparent relationship: The salary of a factory worker, or the purchase price of materials used to create the product. However, business also involves indirect costs, which contribute less directly to the cost object, leading to a complex array of costs to estimate. For example, the rent paid for the production facility is an indirect cost. Likewise, if a company produces all components of a product, the costs associated with producing them must be traced to the end product. The challenge posed here is to determine all of the indirect costs associated with the production as they are not always immediately obvious.

\section{Estimation}

Tracing costs becomes even more complicated when they have been incurred in production multiple goods or services. The main challenge in front of the managers is estimating exactly what part of the rent should go toward a specific product and what part to the other so at the end each product receives its fair percentage of rent. In situations like this the managers rely on cost drivers to help them with the allocation, meaning they look for hints to figure what part of a given service or expense is going toward each cost object.

\section{Time}

Tracing and assigning costs are important but only if it is in efficient way. The company does not benefit financially from endless hours spent trying to determine every single cost. When cost which appear very time consuming to trace to their origin or identify the cost/cost object relationship they have, sometimes it is better to directly distribute those costs based on the best estimation grounds without spending significant amount of time or funds.

\section{Inaccuracies}

Accurate product costs are required so that management can distinguish between profitable and unprofitable products. If the cost system does not capture sufficiently accurately the consumption of resources by products, the reported product costs will be distorted, and there is a danger that managers may drop profitable products or continue production of unprofitable products (1). This is directly related with the previous point of not spending too much time on cost tracing - thus, a company must get the right balance between spending too much or too little effort on it. By more accurately measuring resources consumed by products or other cost objects, a company can identify its sources of profits or losses. A wrong allocation lead to wrong figures in the financial statements eventually leading managers to ineffective decision making.

\section{Pricing}

Pricing decisions are of crucial importance to a firm's survival; a small change in price can cause a significant change in profitability especially in highly competitive markets. Cost allocation affects reported figures in the financial statements and thus the decision usefulness of the financial statement information. As a result, products may be under or overpriced. Company will be selling at a loss or losing market share which also will ultimately generate losses.

\section{COST ALLOCATION}

Cost allocation is the process of tracing, accumulating, and assigning costs to cost objects, such as products, departments, and divisions. The ultimate goal is to link the cost with the cost object that caused it which is accomplished by selecting an appropriate cost - allocation base called a cost driver. Some major costs have an obvious cost driver, such as paper for a book - tonnes of paper consumed; professional labour for an accounting firm - direct labour hours used, hence can be easily allocated to departments, jobs, and projects on an item-by-item basis. Other costs are not important enough to justify being allocated individually. These costs are gathered (pooled) and then allocated together. A cost pool is a assembling of individual costs, which are then allocated using a single cost driver. Basically the cost driver is the factor that the costs were grouped by in the first place. Based on allocation criteria (in this case that would be floor space), building rent and cleaning cost services will most probably end up in the same cost pool.

Direct costs are assigned to production without using allocated costs. The allocation of costs is necessary when the relationship between the costs and the cost objective is indirect. In this case, a basis for the allocation, such as directlabour-hours or tonnes of raw material, is used even though its selection is arbitrary. In 
general, the cost allocation serves the following purposes:

- Provides information for economic decisions - for example: to decide on product mix; to decide on the selling price; to take make-or-buy decision for a specific production component

- Motivates managers and employees - for example: to influence management behaviour and thus promote efficient use of resources. Some companies do not allocate the costs for specific services to encourage their use, and vice versa in other companies these same services are subject to cost allocation in order to motivate the management to make sure the benefits of those justify the cost.

- Justifies costs or compute reimbursement for example: cost products at a fair price

- Measures income and assets for reporting to external parties - for example: to cost inventories and cost of sales for financial reporting to shareholders and bondholders.

Cost allocation is used for financial reporting, planning and control purposes, to distribute costs to departments, inventory items or help with accurate price setting. For example: full costs are important when deciding on selling prices and manufacturing costs are appropriate for asset valuations. Ideally, all purposes would be served simultaneously by a single cost allocation. Unfortunately for most costs the ideal is hard to achieve. Instead, cost allocations are often a source of discontent and confusion for the affected parties. The greatest problems are usually imposed by the fixed costs allocation. In case all four purposes cannot be accomplished simultaneously, the management should try to identify which of the purposes should dominate in the particular situation at hand. Often inventory-costing purposes dominate by default because they are externally imposed.

\section{Traditional Costing Systems}

Traditional costing systems were developed in the early 1900s and are still widely used today. They usually use either the amount of direct labour hours consumed or machine hours used as a base for overhead distribution. In nature, Traditional costing systems are very simplistic and inexpensive to use but are highly likely to cause inaccuracies in the cost distribution and thus estimating an inaccurate cost of production. For example, if the overhead is much higher than the base of allocation - a very small change in the volume of consumed resources can cause a very high increase in the overhead applied. Traditional costing system follow few steps allocation process - assigning all manufacturing overheads to production and service cost centers, reallocating the costs assigned to service cost centers to production cost centers, calculating separate overhead application rate for each production cost center and finally, assigning production cost center overheads to the chosen cost objects. This approach still works well for financial statement reporting, where it is simply intended to apply overhead to the number of produced units for the purpose of valuing ending inventory. In this case there is no consequence from a management decisionmaking perspective.

Traditional costing systems are based on the principle that production overheads are driven by the level of production. This is because the cost drivers used for overhead allocation are all volume-based. This was true in the past, because businesses only produced one simple product or a few simple and similar products. Overheads used to be small compared to other costs in traditional manufacturing and production overheads, such as machine depreciation, will have been a small proportion of overall costs because production was more labour intensive. Now, the situation is much different - in modern manufacturing most of the manual labour is replaced by machines which increased the proportion of overheads over the direct costs. The nature of manufacturing has also changed. Instead of one or few simple and similar products, now companies aim for more diversity and complexity of products to make sure they will satisfy the customers in the highly competitive environment they operate now. Therefore, the consumption of a company's shared resources also varies substantially across products and customers. On the other hand - computer technology has reduced the costs of developing and operating cost systems that track many activities. ABC costing systems solves some of the deficiencies of traditional costing systems.

\section{Activity - based costing (ABC)}

Activity-Based Costing (ABC) should be preferred when many costs are caused by nonvolume-based cost drivers. It distributes overhead to cost objects in a more logical way than traditional absorption. Activity-based costing (ABC) systems first accumulate overhead costs for each of the activities of an organization, and then assign the costs of 
activities to the products, services, or other cost objects that caused that activity. ABC recognizes that the activities causing the cost are also the ones causing the company to consume resources. Let's take for example two different products (A) and (B). Product (A) is a low-volume product but requires regular and costly quality inspections and product (B) is a high-volume product which requires little attention. If the company uses traditional costing the high-volume product (B) will receive the greater portion of the overhead cost due to the many machine hours it uses and very little will be allocated to product (A) which is the main cause of the overhead costs in the first place. The true cost of both products will be distorted, which would have been avoided by using the activity - based approach. Cost-driver activity is measured by the number of transactions involved in the activity and are assigned to products in proportion to the number of quality inspections required for each product. In the $A B C$ system, significant overhead activities (machining, assembly, quality inspection, etc.) and related resources are separately identified and traced to products using cost drivers-machine hours, number of parts, number of inspections, etc. Basically, $\mathrm{ABC}$ expands the number of cost pools that can be used and instead of having all costs in one large overhead cost pool, it pools costs by activity. Appropriate selection of activities and cost drivers allows managers to trace many manufacturing overhead costs to a specific product just like they can do with the direct costs. This helps managers have greater confidence in the costs of products and services reported by activity-based systems. Because activity-based accounting systems are more complex and costly than traditional systems, not all companies use them. But its importance has been growing over the years so is its popularity among the organisations. Activity-based indirect cost allocation is more time-consuming but is also a more accurate method for allocating indirect costs. However, it is not intended to provide an automatic decision, rather to provide more reliable information about the production and their cost and help management to take the best decision from profitability standpoint (2).

\section{ALLOCATION METHODS FOR MULTIPLE SERVICE DEPARTMENT COST}

Support/service departments, are units within a company, which only purpose is to support other departments, and their costs are totally reallocated. Examples include Information systems, Human resources, Legal department etc. The allocation of costs from support departments to operating departments is an important concept, the overall objective of which is to have more accurate product, service and customer costs. All cost allocation methods aim to distribute the cost as fair as possible. However, the most complete method is the one that fully recognizes the interdepartmental services. Interdepartmental services are services that two or more service departments provide to each other.

\section{Direct method}

The most popular method used for allocating costs is the direct method of cost allocation. It is considered the most simple method as it ignores the fact that the various service departments within the company actually offer services to one another. The HR department for example is responsible for hiring staff for the maintenance department and the maintenance department also maintains the HR department's equipment.

The advantage of the direct method is its simplicity and easy application, however, compared to other methods it is considered less accurate as it can lead to distorted calculation of operating departments expenses due to not accounting for the interdepartmental services involved.

\section{Step down method}

The step-down method recognizes that some service departments support the activities in other service departments as well as those in production departments and allocates costs to both. This happens through a sequential process. A sequence usually starts with the department that renders the greatest service (as measured by costs) to the greatest number of other service departments. The last service department in the sequence is the one that provides the least amount of service to other service departments. Once a service department's cost is completely allocated, however, it will not receive proportion of the cost supposed to be allocated back to it from the other service units. Bottomline, the stepdown method allows for partial recognition of support services provided to other support departments which is also seen as the main flaw of this method. However, it is considered a compromise being more accurate than the direct approach but still not taking account of self - consumption. 
A spreadsheet could be used to facilitate the many calculations in the step-down method. It would calculate the percentages of use by remaining support departments and operating departments at each step, and then allocate the support department's cost based on the percentages (3).

\section{Reciprocal method}

The reciprocal method for allocating support department costs is preferred over the direct and step-down methods because it fully recognizes services among support departments. It includes them in defining a support department's reciprocated costs as its own cost plus any interdepartmental costs allocated to it from other support departments.
The reciprocal method is a significant improvement over the direct and the stepdown methods. This method uses a set of independent linear equations that are solved simultaneously. Solving few simultaneous equations by hand is relatively easy (Example 1), however, with the increase of service departments this algebraic approach become cumbersome (4)

Example 1: Simultaneous Equation Method of Service Department Cost Allocation

For this example, we will use a company with two production departments - Dept. X and Dept. Y and two service departments - HR Dept. and IS Dept., the data for which could be found in Table 1.

Table 1. Example 1 Data

\section{DEPARTMENT}

Dept. Overhead before allocation

\section{Services provided}

HR Dept IS Dept

\begin{tabular}{lccc}
\hline Production dept. $\mathbf{X}$ & $2,000.00 €$ & $60 \%$ & $30 \%$ \\
Production dept. $\mathbf{Y}$ & $1,000.00 €$ & $30 \%$ & $40 \%$ \\
HR (service dept.) & $4,200.00 €$ & - & $30 \%$ \\
IS (service dept.) & $3,800.00 €$ & $10 \%$ & - \\
\hline TOTAL dept. Overhead & $\mathbf{1 1 , 0 0 0 . 0 0 €}$ & $\mathbf{1 0 0 \%}$ & $\mathbf{1 0 0 \%}$
\end{tabular}

Step 1 - Set up the equations

Total HR dept cost $=$ HR department cost + cost allocated to HR from IS department; Total IS dept cost $=$ IS department cost + cost allocated to IS from HR department Therefore:

Equation 1: HR $=4200 €+0.30 \mathrm{IS}$; Equation 2: IS $=3800 €+0.10 \mathrm{HR}$
Step 3 - Solve the system of two linear equations with two unknown variables. It has unique solution.

\section{Step 4}

Built the distribution summary (Table 2) using the allocation percentages given in Table 1 to distribute the total reciprocated cost of the two service departments calculated in Step 3.

Table 2. Example 1 Allocation summary of reciprocated cost

\begin{tabular}{lccccc} 
& HR Dept. & IS Dept. & Dept. X & Dept. Y & TOTAL \\
\hline $\begin{array}{l}\text { Overhead before allocation } \\
\text { Allocation }\end{array}$ & $4,200 €$ & $3,800 €$ & $2,000 €$ & $1,000 €$ & $11,000 €$ \\
HR Dept. $(60 \% 30 \%-100 \% * 10 \%)$ & $-5,505 €$ & $551 €$ & $3,303 €$ & $1,652 €$ & $0 €$ \\
IS Dept. $(30 \% 40 \% 30 \%-100 \% *)$ & $1,305 €$ & $-4,351 €$ & $1,305 €$ & $1,740 €$ & $0 €$ \\
\hline TOTAL dept. Overhead & $\mathbf{0 €}$ & $\mathbf{0 €}$ & $\mathbf{6 , 6 0 8 . 2 5} €$ & $\mathbf{4 , 3 9 1 . 7 5} €$ & $\mathbf{1 1 , 0 0 0} €$ \\
*"-100\%"represents the fully allocated cost in each service department & & &
\end{tabular}

Another way uses a matrix approach. Furthermore, the matrix approach can capture complex relationships among many support departments and operating departments. The computed reciprocated costs of each support department can also be allocated to the other support and operating departments using a matrix function (Example 2).

Example 2 - Multiple service departments It is demonstrated with an example with three production departments - Dept. X, Dept. Y and
Sept. Z and four service departments - Dept. A, Dept. B, Dept. C and Dept. D. This could be applied for any number of variables $-n$ production departments and $m$ service departments. Departments data and the percentage of the support services provided to other departments is presented in Table 3. The total for each service department is equal " 0 " since at the end all of its reciprocated costs should be allocated to the other departments. 
Table 3. Example 2 Data

\begin{tabular}{llccccccc} 
& \multicolumn{3}{c}{ Service Departments } & \multicolumn{3}{c}{ Production Departments } & \\
\cline { 2 - 7 } & Dept. A & Dept. B & Dept. C & Dept. D & Dept. X & Dept. Y & Dept. Z & TOTAL \\
\hline $\begin{array}{l}\text { Overhead } \\
\text { Allocation }\end{array}$ & $1,500 €$ & $600 €$ & $2,100 €$ & $1,800 €$ & $2,000 €$ & $1,000 €$ & $6,000 €$ & $15,000 €$ \\
Dept. A & $\mathbf{- 1 . 0 0}$ & 0.05 & 0.02 & 0.08 & 0.35 & 0.20 & 0.30 & 0.00 \\
Dept. B & 0.05 & $\mathbf{- 1 . 0 0}$ & 0.04 & 0.05 & 0.10 & 0.30 & 0.46 & 0.00 \\
Dept. C & 0.20 & 0.06 & $\mathbf{- 1 . 0 0}$ & 0.05 & 0.20 & 0.30 & 0.19 & 0.00 \\
Dept. D & 0.08 & 0.20 & 0.30 & $\mathbf{- 1 . 0 0}$ & 0.10 & 0.05 & 0.27 & 0.00 \\
\hline
\end{tabular}

*"-1.00" displayed for each service department represents the fully allocated reciprocated cost.

\section{Step 1}

Set up the equations (same as in Example 1, but modified into a matrix format).

Equation 1: Dept A 1.00A - 0.05B - 0.20C $0.08 \mathrm{D}=1500 €$

Equation 2: Dept B 0.05A - 1.00B - 0.06C $0.20 \mathrm{D}=600 €$

\begin{tabular}{|c|c|c|}
\hline S & $\mathrm{x}$ & $\mathrm{X}$ \\
\hline$+1.00-0.05-0.20-0.08$ & & A \\
\hline$-0.05+1.00-0.06-$ & $\mathrm{x}$ & B \\
\hline $\begin{array}{l}0.20 \\
-0.02-0.04+100-\end{array}$ & & $r$ \\
\hline 0.30 & & \\
\hline $\begin{array}{l}-0.08-0.05-0.05+ \\
1.00\end{array}$ & & $\mathrm{D}$ \\
\hline
\end{tabular}

S matrix (4 x 4) = reciprocated services among service departments

$\mathbf{X}$ matrix $(4 \times 1)=$ variables A, B, C, D used to note the service department reciprocated costs $\mathbf{K}$ matrix $(4 \times 1)=$ constant; overhead for each department before any allocations

The reciprocated cost solution for each department is computed mathematically using a spreadsheet software.
Equation 3: Dept C 0.02A - 0.04B - 1.00C $0.30 \mathrm{D}=2100 €$

Equation 4: Dept D 0.08A - 0.05B - 0.05C $1.00 \mathrm{D}=1800 €$

Step 2

Using Table 3, build the matrix relationship and use to calculate the reciprocated total cost for each department.

$\mathrm{K}$

$1,500 €$
$600 €$
$2,100 €$
$1,800 €$

Solution $\left|\begin{array}{l}\mathrm{A} \\ \mathrm{B} \\ \mathrm{C} \\ \mathrm{D}\end{array}\right|=\left|\begin{array}{l}2,313 € \\ 1,326 € \\ 2,858 € \\ 2,194 €\end{array}\right|$

\section{Step 3}

Compute the reciprocated cost allocation to all departments by multiplying two matrices based on the values found in Step 2
R
$2313+0.00+0.00+$
0.00
$0.00+1326+0.00+$
0.00
$0.00+0.00+2858+$
0.00
$0.00+0.00+0.00+2$
194

$\mathbf{x}\left|\begin{array}{cccccccc}-1.00 & 0.05 & 0.02 & 0.08 & 0.35 & 0.20 & 0.30 \\ 0.05 & -1.00 & 0.04 & 0.05 & 0.10 & 0.30 & 0.46 \\ 0.20 & 0.06 & -1.00 & 0.05 & 0.20 & 0.30 & 0.19 \\ 0.08 & 0.20 & 0.30 & -1.00 & 0.10 & 0.05 & 0.27\end{array}\right|=\mathbf{A}$


$\mathbf{R}$ matrix $(4 \times 4)=$ reciprocated total cost of service departments

$\mathbf{P}$ matrix $(4 \times 7)=$ The percent of the support services provided to other departments (Table 3)

Table 4. Example 2 Allocation summary of reciprocated cost Service Departments

Production Departments

\begin{tabular}{|c|c|c|c|c|c|c|c|c|}
\hline & Dept. A & Dept. B & Dept. C & Dept. D & Dept. X & Dept. Y & Dept. Z & TOTAL \\
\hline $\begin{array}{l}\text { Overhead } \\
\text { Allocation }\end{array}$ & $1,500 €$ & $600 €$ & $2,100 €$ & $1,800 €$ & $2,000 €$ & $1,000 €$ & $6,000 €$ & $15,000 €$ \\
\hline Dept. A & -2313 & 116 & 46 & 185 & 810 & 463 & 694 & 0.00 \\
\hline Dept. B & 66 & -1326 & 53 & 66 & 133 & 398 & 610 & 0.00 \\
\hline Dept. C & 572 & 171 & -2858 & 143 & 572 & 857 & 543 & 0.00 \\
\hline Dept. D & 176 & 439 & 658 & -2194 & 219 & 110 & 592 & 0.00 \\
\hline $\begin{array}{l}\text { TOTAL } \\
\text { dept. } \\
\text { overhead }\end{array}$ & $0 €$ & $0 €$ & $0 €$ & $0 €$ & $3,733 €$ & $2,827 €$ & $8,439 €$ & $15,000 €$ \\
\hline
\end{tabular}

The major advantage of reciprocal method is that it fully takes into account the interdepartmental services and is therefore considered a more accurate method of all three and the most complex at the same time which is the reason it is not widely used among the managers. The use of a computer software could solve the complexity issue involved in this method and make it more popular, but of course this will come at a price. The companies then need to weigh the benefits obtained from more accurate cost allocation against the costs required to implement the reciprocal method.

\section{SURVEY RESULTS}

This study seeks to determine how companies of different size and industry deal with the problem of allocation of multiple service departments cost. Therefore, this study is conducted to shed some light on how the issue of allocation is addressed when multiple service departments costs are present in an organisation.

The objective of the study is to establish the cost allocations methods used for multiple service department cost. For the purposes of the study, 64 companies were selected, and asked to fill in a questionnaire on their allocation method in terms of service department cost allocation methods, overhead
A matrix $(4 \times 7)=$ The allocation of service departments to all other departments (Table 4) 


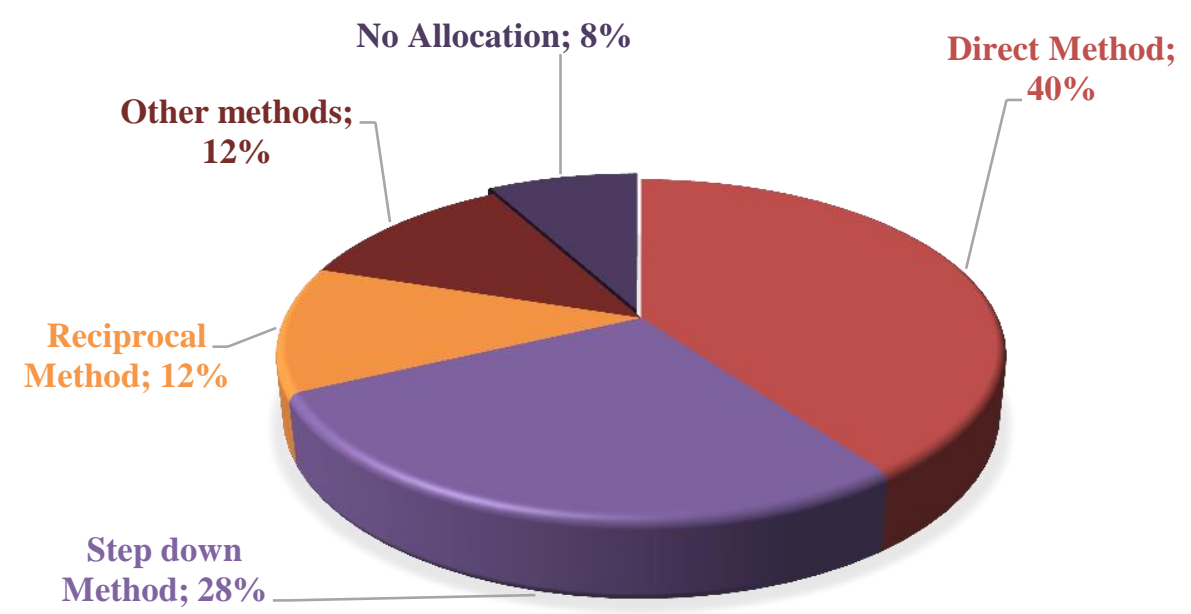

Chart 1: Methods used for allocation of multiple service departments cost

\section{CONCLUSION}

The methods outlined for allocating indirect production costs have their advantages and disadvantages. The presumption is that the most detailed allocation of costs to production costs would provide more complete and reliable information for assessing the cost of products. This is essential in order to place a competitive product on the market, take effective managerial decisions as well as monitoring company's performance and making strategic analysis. These points are recognized by finance leaders and it is expected that companies will increase investments in IT infrastructure and would use more complex and theoretically advanced cost allocation methods in the future.

\section{REFERENCES}

1. Drury, Colin (2018). Management and Cost Accounting, 10th Edition: Cengage Learning

2. Dr. Bashir Al-Halabi1, Nabil \& Dr. Fareed Shaqqour, Omar (2018). The Effect of Activity-Based costing (ABC) on Managing the Efficiency of Performance in Jordanian Manufacturing Corporations An Analytical Study: Retrieved from http://www.sciedu.ca/

3. Hansen, Don R. \& Mowen Maryanne M. (2018). Cornerstones of Cost Management: Cengage Learning

4. Mistry, Jamshed Jal (2019). Cost Allocation and Information Technology: IEEE 